\title{
Estallido social, memoria y derechos humanos
}

\author{
Social Outbreak, Memory and Human Rights \\ Carmen Pinto Luna \\ Comisión Nacional de Derechos Humanos, Chile \\ ccpintol@gmail.com
}

\section{Resumen:}

El llamado estallido social iniciado el 18 de octubre de 2019 si bien fue inesperado en su magnitud, no lo fue en su contenido, en su origen están sin duda las violaciones a los Derechos Humanos, el medio del cual se valieron los detentadores del poder dictatorial para imponer un nuevo orden político, económico, social y cultural, sustentado en un Estado subsidiario que lo despojó de sus obligaciones de garantizar derechos básicos, tal como lo dispone la normativa internacional de los Derechos Humanos e impidió sistemáticamente al pueblo chileno decidir su destino de manera soberana. Como lo han señalado los jóvenes que iniciaron este estado de rebeldía, no son treinta pesos, en alusión al aumento del valor del transporte metropolitano, son treinta años a la sombra de una dictadura cuya principal herencia es la Constitución de 1980, y su ya famoso Tribunal Constitucional, una real tercera Cámara.

Palabras Clave: Estallido social, Memoria y Negacionismo, Derechos Humanos, Nueva Constitución.

\section{Abstract:}

Although the so-called social outbreak began on October 18, 2019, and it was unexpected in its magnitude, though expected in its content; its origins are undoubtedly the violations of Human Rights, the means by which the defenders of the dictatorial power imposed a new political, economic, social and cultural order, sustained in a subsidiary State that stripped it of its obligations to guarantee basic rights, as provided by international human rights law and systematically prevented the Chilean people from deciding their sovereign destiny. As the young people who started this state of rebellion have pointed out, they are not thirty pesos, alluding to the increase in the value of metropolitan transport, they are thirty years in the shadow of a dictatorship whose main legacy is the 1980 Constitution, and its infamous Constitutional Court -a real third Chamber.

KEYwORDs: Social Outbreak, Memory and Deniability, Human Rights, New Constitution.

Durante los 17 años de Dictadura cívico-militar, la comunidad internacional agrupada en la Organización de Naciones Unidas condenó al Estado chileno por su política permanente de violación sistemática de los derechos humanos en nuestro país. Chile fue un paria en el sistema internacional, siendo apuntado por el dedo por el concierto de naciones, por su abierta vulneración y desconocimiento de la normativa internacional de Derechos Humanos que Naciones Unidas había impulsado desde su creación en 1945.

El presente es por tanto una consecuencia necesaria del pasado, otorgándole sentido a la protesta; pasado que instala su presencia como verdad indesmentible, situación inesperada por cierto para muchos. Si quisiéramos darle una categoría a esta memoria de los treinta años, y tal vez un poco más, es sin duda una memoria subversiva, porque actúa como crítica a un modelo inhumano, es memoria de la disconformidad que estimula el recuerdo de algo ya acontecido. Es la memoria de las violaciones a los derechos humanos de manera sistemática. Es la memoria de acumulación de hechos que parecían haberse naturalizados y que irrumpen en el presente trayéndonos los peligros de otra época, de transformaciones anunciadas que no se hicieron realidad y por lo tanto habla de las condiciones objetivas que provocaron el estallido social cuya reflexión debiera ser que el camino recorrido desde el término de la dictadura no fue el correcto, en todo caso no fue la transición ejemplar de la cual algunos actores políticos hablan. 
El 18 de octubre 2019 puso en juego la alteración sustantiva de lo establecido recibiendo la adhesión de millones de personas, dándole la bienvenida a un pasado doloroso que jamás saldó sus deudas en materia de verdad, justicia, reparación y fue incapaz de implementar medidas que dieran garantía de no repetición, que permitieran que Nunca Más el país volviera a repetir la barbarie del exterminio, sufrida durante 17 años. Con esto se ha fracturado el tiempo unificándolo en un mismo movimiento, nos sacudió de manera brutal, recobrando la memoria todo su peso en la condición colectiva de la misma.

En efecto, es necesario recurrir a la memoria para comprender, por ejemplo, la crueldad desplegada por el aparato represivo del Estado, representado por Carabineros y sus Fuerzas Especiales, actuando según un modelo creado en dictadura y que se fue perfeccionando en los años de transición. Prácticas tales como privar de la visión parcial o totalmente a más de 400 personas, mantener más de 2.500 personas, la mayoría jóvenes, en prisión preventiva dictadas en procesos seguidos a partir del 18 de octubre no admiten en la actualidad ninguna explicación. Lamentablemente, justicia y memoria no se conjugan.

El alto número de encarcelados por manifestarse en las calles en contra del actual modelo de sociedad, contrasta con la situación de los violadores de los derechos humanos, en el mismo período. Según las cifras del Ministerio Público, de las más de 4.500 causas iniciadas por violaciones a los derechos humanos cometidas por agentes del Estado, sólo en alrededor 38 de ellas hay formalizados ${ }^{1}$, y debemos recordar que aún tenemos 1.192 detenidos desaparecidos como una llaga abierta que debiera avergonzarnos como sociedad.

La movilización social ha abierto una brecha en la herencia de ese pasado doloroso, que nos ha hecho vivir a la sombra de la dictadura, como lo es la Constitución de 1980, creando las condiciones para la redacción de una nueva Constitución y junto con ello de una agenda social verdaderamente estructural. Es así como el principal órgano de Naciones Unidas sobre Derechos Humanos (ACNUDH) ha señalado, en relación con el actual proceso constituyente, la necesidad de asegurar que el proceso de elaboración de una nueva Constitución sea inclusivo, participativo, transparente, que garantice la paridad de género y la participación de los pueblos indígenas y todos los demás sectores de la sociedad, lo que está en plena concordancia con las exigencias mayoritarias de los chilenos y que constituyen requisitos básicos, para dar legitimidad al proceso constituyente en curso y de ejercer el derecho de libre determinación.

Del mismo modo, al recomendar que los Derechos Humanos deben estar en el centro de este debate nacional, ha subrayado que el eje central en la redacción de la nueva Constitución está dado justamente por el respeto y garantía de los Derechos Humanos consagrados en los Pactos y Convenciones suscritos y ratificados por el Estado de Chile, cuyo cumplimiento irrestricto no es posible desconocer.

El llamado despertar de Chile iniciado a partir del 18 de octubre 2019 con miles de jóvenes evadiendo el pasaje del transporte público, no es otra cosa que un llamado a recobrar la dignidad, por ende la recuperación no sólo de la soberanía popular perdida o al menos extraviada, lo que supone reinstalar plenamente la posibilidad de ejercer la soberanía política, a través de una nueva institucionalidad, sino que además supone recuperar también plenamente la soberanía económica, que nos permita disponer libremente de sus riquezas y recursos naturales, única forma de proveer al desarrollo económico, social y cultural del país. Ha reinstalado la necesidad de avanzar en este camino como solución de fondo al legítimo descontento expresado por el pueblo chileno y como respuesta a la situación de ingobernabilidad en que se encuentra sumido nuestro país, producto de la ineficacia e incapacidad de las actuales autoridades para enfrentar debidamente la ira e indignación social de un pueblo cansado de tanta humillación y vulneración de sus derechos humanos fundamentales.

Para tal efecto, resulta indispensable elaborar una Nueva Constitución que establezca a través de un modo genuinamente participativo, como la Asamblea Constituyente, que pareciera ser que cuenta con la mayor aprobación popular, para las nuevas reglas del juego democrático, cuya base de legitimidad sea la más amplia participación de la sociedad chilena y sus organizaciones sociales y políticas, y cuya redacción tenga como referencia ineludible, el cumplimiento irrestricto de las obligaciones internacionales que tiene el Estado chileno en materia de Derechos Humanos, las que comprenden, según los órganos del Sistema de Naciones 
Unidas, las obligaciones de respetar, proteger y garantizar los derechos humanos, como el derecho a la Vida, la Libertad, y los derechos a la Educación, a la Salud, a la Seguridad Social, a una Remuneración justa, entre otros.

Gracias a este movimiento tan masivo y mayoritario, se impone por cierto, la elaboración de una nueva Constitución Política como una oportunidad única para poner al día al Estado de Chile en el cumplimiento irrestricto de sus obligaciones internacionales en materia de Derechos Humanos, y aunque resulte reiterativo, establecidas en los diversos instrumentos internacionales, las que comprenden las obligaciones de respetar, proteger y garantizar los derechos humanos y la de adoptar medidas de efectivo cumplimiento, teniendo siempre presente la integralidad e indivisibilidad de los mismos.

Cuando afirmamos que el presente es una consecuencia del pasado, es necesario recordar que durante estos últimos años hemos visto crecer y desarrollarse una potente corriente negacionista en el país, lo que llevó a algunos parlamentarios, gracias a la presión constante y sostenida en el tiempo por las organizaciones de derechos humanos, a proponer la sanción del Negacionismo, a través de una iniciativa legal, discusión inconclusa, pero que se inscribe en la necesidad de resguardar debidamente la Memoria de las víctimas y un aporte indiscutido a la tarea de evitar la repetición de la trágica experiencia vivida por el pueblo chileno.

Quienes se oponen a su sanción, arguyen equivocadamente que se estaría vulnerando con ello la libertad de expresión. Al respecto, cabe puntualizar que la libertad de expresión no es un derecho humano absoluto, sino que admite limitaciones y restricciones. Efectivamente, el derecho a la honra y dignidad de las personas establecido en el artículo 12 de la Declaración Universal de Derechos Humanos, prima por sobre la libertad de expresión. Y la Convención Americana de Derechos Humanos así lo ratifica, al establecer en su artículo 13 núm. 5, la prohibición de toda apología del odio nacional, racial o religioso que constituyan incitaciones a la violencia. A mayor abundamiento, la legislación penal común, sanciona el delito de injurias y calumnias.

Por otra parte, nadie podría poner en discusión que la negación de los crímenes contra la Humanidad consignados en los cuatro Informes oficiales del Estado de Chile, constituyen una grave ofensa a la Memoria y a la dignidad de las víctimas y sus familiares. Quienes invocan la libertad de expresión como argumento, nada dicen respecto del último Informe emitido en al año 2015 por el Relator del Sistema Interamericano ${ }^{2}$ encargado de supervisar su debido cumplimiento, que consignó que la falta de pluralismo informativo en Chile, producto de la alta concentración de la propiedad de los medios de comunicación, constituía una grave vulneración de la libertad de expresión en nuestro país.

Esta iniciativa legal sería innecesaria si el Estado de Chile hubiera cumplido con sus obligaciones internacionales consistentes en la adopción de políticas y medidas necesarias y suficientes que garantizaran efectivamente el Nunca Más.

El actual gobierno no ha tenido una lectura correcta de las demandas sociales y ha llegado tarde a proponer soluciones que no dejan satisfecho a nadie, por el contrario ha recrudecido un estado de represión, ha instaurado un Estado de Emergencia y Toque de Queda, lo que significa un grave retroceso para los Derechos Humanos y una grave afrenta a la Memoria de nuestro país, especialmente para los familiares de víctimas y para los sobrevivientes, sin entender que la solución a la crisis, no puede ser militar sino que política. No podemos olvidar que hace 46 años, los sectores políticos que hoy nos gobiernan, recurrieron a las Fuerzas Armadas para poner freno al proceso de transformaciones sociales y de mayor justicia social que impulsaba el gobierno legítimamente constituido de Salvador Allende, y que el golpe militar que promovieron, dio inicio a la implementación de una política de exterminio que trajo consigo miles de víctimas de violaciones a los Derechos Humanos, cuyas secuelas aún persisten y están presente en cientos y miles de pancartas exhibidas en las múltiples protestas a lo largo del país.

En efecto, es de conocimiento nacional e internacional que, en el contexto de las diversas manifestaciones y movilizaciones, el presidente de la República ha declarado tempranamente el Estado de Excepción Constitucional de Emergencia en distintas regiones, provincias y comunas del país, fundándose en graves alteraciones al orden público. En el caso de la Región Metropolitana de Santiago, se trata del Decreto 
Supremo N. ${ }^{4}$ 42, publicado en el Diario oficial el 19 de octubre de 2019, respecto de la Provincia de Santiago y de Chacabuco, así como las comunas de Puente Alto y San Bernardo de la Región Metropolitana ${ }^{3}$, y del Decreto Supremo N. ${ }^{\circ}$ 49, publicado en el Diario oficial el 20 de octubre de 2019 que extiende la declaración de Estado de Excepción Constitucional de Emergencia a toda la Región Metropolitana ${ }^{4}$. En razón de dichos Decretos Supremos, el General Jefe de la Defensa Nacional, ha decretado sucesivos toques de queda, restringiendo dramáticamente la libertad ambulatoria constitucional e internacionalmente garantizada.

Es en virtud de esta situación, que muchas personas han sido sorprendidas infringiendo el señalado toque de queda, han sido detenidas y retenidas, en algunos casos hasta el fin del toque de queda y en otros, puestos a disposición de tribunales. En otros casos, durante las manifestaciones realizadas en el horario no cubierto por el toque de queda, muchas otras personas han sido detenidas y retenidas por las supuestas comisiones de ilícitos o infracciones. Lo anterior, sin perjuicio de situaciones aún más graves, que pueden constituir lesiones, aplicación de tormentos, torturas, e incluso muertes, las cuales, si bien no son objeto de este recurso, dan cuenta de la gravedad de la situación.

$\mathrm{Al}$ respecto, diversas instituciones, organizaciones de la sociedad, grupos de voluntarios y abogados particulares se han organizado y coordinado para ejercer y ofrecer la defensa ante las personas detenidas y retenidas, cautelando sus derechos y garantías, y controlando que en momento alguno sufran vejaciones de ningún tipo, entre ellas la Comisión Chilena de Derechos Humanos, el Instituto Nacional de Derechos Humanos (INDH), la Defensoría Penal Pública, la Defensoría Jurídica de la Universidad de Chile, la Asociación de Abogadas Feministas (ABOFEM), y muchas otras.

Sin embargo, y al momento de llevar a cabo las acciones de búsqueda de antecedentes, entrevistas con personas detenidas, cotejo de información respecto de la identidad de personas detenidas, obtención de datos para defensas judiciales, lectura e información de derechos, aviso a familiares y conocidos del paradero y condiciones de la detención, verificación de la constatación de lesiones y en general, muchas comisarías, retenes y unidades policiales han dificultado o llanamente negado la entrega de información o impedido la comunicación con las personas privadas de libertad en esas circunstancias, y por tanto la identidad, estado y circunstancias de la detención de las personas detenidas no ha podido ser contrastada con ninguna información oficial.

Esto quiere decir que ni el Alto Mando de Carabineros ni la Dirección General de la Policía de Investigaciones de Chile ha emitido un comunicado oficial con el total de nombres, situación, estado, circunstancias e imputaciones de personas detenidas. Todo lo anterior constituye una ilegalidad que conculca el Derecho Constitucional a la Libertad Personal y Seguridad Individual establecido en el art. N. ${ }^{\circ} 19$ N. 7 de la Constitución Política de la República.

Por lo anterior, podemos afirmar sin lugar a equivocaciones, que el número de detenidos, lesionados, amedrentados, torturados, es muchísimo mayor a cualquier cifra oficial que se haya publicado y por lo mismo también creemos no incurrir en errores cuando afirmamos que en Chile se están violando masiva y sistemáticamente los derechos humanos, perfeccionando incluso el modelo ya conocido en el pasado reciente.

Poco antes del estallido social, el Presidente Sebastián Piñera, había señalado que el país era un oasis dentro del concierto de América Latina, con este discurso exitista pretendía aplicar su programa eludiendo cambios esenciales, contando para ello con la aparente inmovilización social, por años sometida a una política de consensos que puso término a las esperanzas de las grandes masas dando paso a la sospecha en la clase política y a la pérdida de credibilidad en las instituciones, incluido los partidos políticos, una mayoría dejó de creer en el escrutinio del sufragio universal y es así como el actual presidente fue elegido con una mayoría ficticia, ya que sólo un 46\% del padrón acudió a las urnas, el $54 \%{ }^{5}$ restante no ejerció su derecho a voto en la convicción de que la elección mediante sufragio no era sinónimo de democracia, señal clara del descontento, que muy pocos expertos quisieron ver.

En conclusión, este estallido social es una consecuencia del pasado, ligado a una memoria de violaciones de derechos humanos, se venía gestando desde hace mucho tiempo con señales sectoriales clarísimas, el clima 
se hizo propicio porque el actual presidente conjuga dos características que lo hacen más vulnerable que a sus predecesores a los ojos de las nuevas generaciones que no están dispuestas a seguir bajo un sistema indigno: políticamente representa el neo liberalismo extremo y económicamente forma parte de la elite financiera del país.

\section{Notas}

1 Las cifras se fueron elevando de forma dramática: Fiscalía eleva a 5.558 las víctimas que denuncian violaciones a los Derechos Humanos desde el inicio de las manifestaciones sociales (31 de enero 2020). Fiscalía de Chile. Recuperado a partir de: http://www.fiscaliadechile.cl/Fiscalia/sala_prensa/noticias_det.do?noticiaId=17285

2 Comisión Interamericana de Derechos Humanos. (2015). Informe de la Relatoría Especial para la Libertad de Expresión (volumen 2). Recuperado a partir de: http://www.oas.org/es/cidh/expresion/docs/informes/anuales/InformeAnual2 015RELE.pdf

3 Ministerio del Interior y Seguridad Pública. Declara Estado de Excepción Constitucional de Emergencia en la Provincia de Santiago y Chacabuco, y las comunas de Puente Alto y San Bernardo (18 de octubre de 2019). Diario Oficial. Recuperado a partir de: https://www.diariooficial.interior.gob.cl/publicaciones/2019/10/19/42481-B/01/1671764.p df

4 Ministerio del Interior y Seguridad Pública. Extiende Declaración de Estado de Excepción Constitucional de Emergencia a toda la Región Metropolitana (20 de octubre de 2019). Biblioteca del Congreso Nacional. Recuperado a partir de: https://www.bcn.cl/leychile/navegar?idNorma=1137858

5 Díaz, F. y López, A. Más de la mitad del padrón no fue a votar y participación vuelve a caer (19 de noviembre de 2017). La Tercera. Recuperado a partir de: https://www.latercera.com/noticia/mas-la-mitad-del-padron-no-fue-votar-partici pacion-vuelve-caer/ 